\title{
A STUDY OF THE FIVE ESSENTIAL COMPONENTS OF ORGANIZATIONAL CLIMATE AND ACADEMIC PERFORMANCE INDICATORS
}

\author{
Peter Gathu Ruhiri \\ Grand Canyon University, USA.
}

DOI: 10.46609/IJSSER.2021.v06i01.002 URL: https://doi.org/10.46609/IJSSER.2021.v06i01.002

\begin{abstract}
Workplace climate has been under scrutiny as a factor that shapes social facilitation, interaction and productivity in organizations. The goal of the study was to reveal the extent to which the 5Essentials of school climate correlates with academic performance. The methodology adopted was quantitative with a correlation design. Linear regression analysis and two-tailed correlation matrix were used to show correlations and rank the predictor's effect on criterion for 186 schools. Results indicated on average, $40.8 \%$ of reading scores were explained by parental involvement, supportive environment and ambitious instruction; and these variables statistically significantly predicted AYP in reading, $\mathrm{F}(6,107)=12.186, \mathrm{p}<.05, \mathrm{R} 2=.728$. Similarly, $49.45 \%$ mathematics scores was explained by parental involvement and supportive environment that statistically significantly predicted AYP in mathematics; $F(6,107)=11.622, \mathrm{p}<.05, \mathrm{R} 2=$ .577 . On average, $10.8 \%$ of graduation rate was explained mostly by supportive environment that statistically significantly predicted AYP in graduation rate, $\mathrm{F}(6,107)=3.057, \mathrm{p}<.05, \mathrm{R} 2=$ .146. Overall, out of the five predictors only two had positive coefficients and significant levels of $\mathrm{p}<0.05$ (parental involvement and supportive environment). These findings support the argument fronted by the theory of action, which suggested if schools embrace some of the 5Eessentials, they are likely to improve their learner's achievement. Therefore, schools should consider embracing the positively significant five essentials because they may promote student learning and achievement.
\end{abstract}

Keywords: Five Essentials, School/Organizational Climate, Student Achievement

\section{Introduction}

This study investigated to what extent organizational climate affected high schools' performance given in mathematics, reading and graduation rate for high schools in low social economic schools in the Midwestern U.S school district. Williams, and Corkin (2011) defined school 


\section{International Journal of Social Science and Economic Research}

ISSN: $2455-8834$

Volume:06, Issue:01 "January 2021"

climate as the quality and character of life within a school that is shaped by its organizational structure, instructional practices, interpersonal relationships, objectives, customs, and overarching values, and the manner in which school leaders implement or influence them. School climate consists of a multitude of variables, as well as several methodologies, theories, and models that have been used to describe and measure the concept. This has resulted in a body of research that is not easily defined (Welsh, 2000).

Past researchers have conducted studies designed to determine whether relationships exist between school climate and other factors present in a school environment. White, La Salle, Ashby, and Meyers (2014) conducted such a study to determine the relationship between school climate and various behaviors related to bullying. They also addressed whether grade level or gender had moderating effects on this relationship. Based on the format of their study, and to contribute to the existing knowledge base, this study correlated school climate and Adequate Yearly Progress (AYPs) in mathematics, reading and graduation rate in low socioeconomic status (SES) high schools in the Midwestern U.S., factors that have not been studied widely at the high school level.

The goal of this study was to fill the gap in the literature by using data gathered from high schools from a low SES school district in the Midwestern U.S. by conducting a correlational study. The study correlated AYP scores in mathematics, reading and graduation rate for the high schools in the district measured using the Prairie State Achievement Exam (PSAE) and the five essential components of organizational climate that are related to positive school climates. The five dimensions that affect school climate were developed by the University of Chicago and are: (1) effective leadership; (2) collaborative teachers; (3) parental involvement; (4) ambitious instruction, and (5) supportive environment.

A literature review indicated that school climate appears to have converged on five common domains: effective leadership; supportive environment; collaborative teachers; ambitious instruction, and involved families (Sebastian \& Allensworth, 2012). The review further revealed that most instruments used to measure school climate address student-teacher relationships adequately. However, the instruments fail to assess peer relationships well, a factor that is included in the 5Essentials survey that was developed to be a comprehensive measure of school climate.

When the variability in study designs and sample populations of a plethora of studies are considered, the literature reviewed has reached one broad conclusion that school climate is a critically important contextual variable, in that a favorable climate influences academic performance positively. According to Wang et al. (2014), a positive school climate is associated with teacher efficacy, as well as students' positive behavioral, social, and academic outcomes. Thompson and Crank (2010) demonstrated in their study that a favorable school climate yields 


\section{International Journal of Social Science and Economic Research}

ISSN: $2455-8834$

Volume:06, Issue:01 "January 2021"

high achievement. Nevertheless, the high stakes and pressure placed on teachers and administrators to meet school AYPs may be viewed as sanctions to replace those who do not attain AYPs. In turn, this can become counterproductive in developing a positive school climate (Thompson \& Crank, 2010). The problem of historical variability on school climate fails to define clearly how school climate affects such factors as achievement, graduation rate, bullying, the character and quality of school life, norms, interpersonal relationships, teaching and learning practices, values, goals, and organizational structures (Mehta, Cornell, Fan, \& Gregory, 2013). This study intends to contribute to the diversity of school climate in areas that still need research.

Therefore, to contribute to the existing knowledge base, this study correlated school climate and school AYPs measures in mathematics, reading and graduation rate in a low SES school district, factors that have not been studied widely at the high school level. Researchers studied the relationship between school climate and achievement in elementary schools, and, like others, found that a positive school climate contributed to positive achievement in schools (DiStefano, Monrad, May, McGuiness, \& Dickenson, 2007). However, they suggested that because their study was conducted in the context of elementary schools, follow-up studies should collect data in both middle schools and high schools. Miller (2010) also conducted a study that found positive school climate influenced a school's achievement of AYPs. Like most other studies, this study was conducted in an elementary school and Miller (2010) also suggested that further studies should include middle and high schools. To this end, the current research study undertaken herein can be viewed as the much-needed follow-up study suggested by these authors as it targets high schools rather than elementary schools.

Barile et al. (2012) suggested that teaching climate, as an element of school climate, is associated with lower rates of student dropout. These authors suggested that further research should investigate other factors of school climate related to student achievement and retention that yield higher graduation rates. O’Malley, Voight, Renshaw, and Eklund (2014) identified family structure and school climate as factors that affect student achievement. Other researchers identified peer victimization as a contextual variable of school climate that affects students' GPAs negatively (Weijun et al., 2014). Urick and Bowers (2014) suggested that the principal perception of the student academic climate as an element of the wider school climate may have a direct effect on student achievement. Bektas and Nalcaci (2013) identified teacher behavior, achievement orientation, and perceptions of a safe school learning environment as aspects of school climate and stated that these factors affect students' academic achievement. McCoy, Roy, and Sirkman (2013) investigated how higher neighborhood crime decreases learners' socioemotional safety, but did not predict the academic rigor of neighborhood schools.

These dimensions of school climate indicate that it is indeed predictive of student academic achievement. However, each of the studies reviewed addressed one, two, or three elements of 


\section{International Journal of Social Science and Economic Research}

ISSN: $2455-8834$

Volume:06, Issue:01 "January 2021"

school climate and suggested that future studies should focus exhaustively on the other dimensions that constitute school climate. Therefore, the current study advances most of the previous studies by conducting a correlational research among the 5Essentials elements of school climate with the AYPs measures of PSAE in mathematics, reading and graduation rate of a low SES school district in Midwestern U.S. Because all of the research reviewed has indicated that school climate has a strong influence that affects school policies, the goal of this study was to advance our understanding of the relationship that prior research has established between school climate and student achievement in a school district considered as low income. Unlike many of the past studies that have analyzed the effects of a few elements of school climate on achievement, this study combined all five major elements to further clarify the findings on school climate and its effects on student achievement among high schools in a region with low SES demographics.

\subsection{Research Questions and Hypotheses}

The researcher stated the following three research questions and corresponding hypotheses:

RQ1: To what extent are the five essential components of organizational climate related to AYP in mathematics in low SES high schools in Midwestern U.S.?

H10: There are no statistically significant relationships between the five essential components of organizational climate and AYP in mathematics in low SES high schools in Midwestern U.S.

H1A: There are statistically significant relationships between the five essential components of organizational climate and AYP in mathematics in low SES high schools in Midwestern U.S.

RQ2: To what extent are the five essential components of organizational climate related to AYP in reading in low SES high schools in Midwestern U.S.?

H20: There are no statistically significant relationships between the five essential components of organizational climate and AYP in reading in low SES high schools in Midwestern U.S.

H2A: There are statistically significant relationships between the five essential components of organizational climate and AYP in reading in low SES high schools in Midwestern U.S.

RQ3: To what extent are the five essential components of organizational climate related to graduation rate in low SES high schools in Midwestern U.S.? H30: There are no statistically significant relationships between the five essential components of organizational climate and graduation rate in low SES high schools in Midwestern U.S.

H3A: There are statistically significant relationships between the five essential components of organizational climate and graduation rate in low SES high schools in Midwestern U.S.

\section{Research Methodology}




\section{International Journal of Social Science and Economic Research}

ISSN: $2455-8834$

Volume:06, Issue:01 "January 2021"

The study adopted quantitative approach. A quantitative approach was suitable because it allowed statistical analysis through inferential and descriptive statistics (Punch, 2013). In addition, a quantitative study allowed statistical correlation of the 5Essentials of school climate and AYP measures as given by PSAE scores in mathematics reading and graduation rate of high schools from a low SES school district in Midwestern U.S.

The research adopted correlational research design. The five elements of school climate were correlated using multiple linear regression on the set of three AYP measures of achievement in mathematics, reading and graduation rate as given by high school PSAE scores. The 5Essentials of organizational climate and the three school AYP measures were correlated to gain an understanding of the possible influence of school climate on academic performance and graduation rate. The independent and dependent variables were analyzed using multiple linear regression to measure the strength of their association and give an indication of whether variables had a strong or weak correlation.

The data source for this study was online public records. Specifically, high school AYPs scores for mathematics, reading and graduation rate were gathered from interactive online scorecards. The secondary data were gathered from 186 high schools in the district with a total on 761 elementary, middle and high schools. The researcher chose to include the entire population of all 186 high schools in the district as the data sources for this study. A priori power analysis was conducted using G*Power (Faul, Erdfelder, Buchner, \& Lang, 2009) which gave a minimum of 92 schools required to conduct a study with adequate statistical significant. The selected high schools had a population of approximately 400,545 students (www.ccsr.uchicago.edu, 2015). Selecting such many schools (entire high school population) did not only lower the study's standard error/ sampling variability, but it also increased the chances of finding statistically significant mean correlations (Kupzyk, 2011).

This study adopted a stochastic longitudinal approach and utilized data that reflected observations made between time series that was close together during the 2012 to 2014 school years. The researcher retrieved data on high school climate as collected by CCSR using the 5Essentials survey instrument.

In this study, 5Essentials interval score were tabulated against the AYP given by PSAE percentage scores in mathematics, reading and graduation rate of each high school from a low SES school district. Each school had its 5Essentials elements tabulated in a matrix next to its three AYP scores in mathematics, reading and graduation rate. With these data, statistical multiple linear regression was conducted to establish the strength of their correlation $\left(\mathrm{r}^{\wedge}(2)\right)$. Then a more detailed step-wise method of linear regression was conducted to give a general indication of how independent variable correlated with dependent variable andthen interpretations were made for the 2012 to 2014 high school data. 


\section{International Journal of Social Science and Economic Research}

ISSN: $2455-8834$

Volume:06, Issue:01 "January 2021"

Every variable was addressed by its own linear regression. Therefore, there were different regression models as there were the variables. Using the interval of the 5Essentials high school data retrieved from online secondary sources, different frequency procedures were used to compute the mean, standard deviation, skewness, and kurtosis of both dependent and independent variables. This was computed using the SPSS program together with other multiple sets of statistical analysis results.

The validity of this quantitative study was determined by a set of three questions and six hypotheses that aided in investigating whether a correlation existed between the dependent and independent variables (school climate given by 5Essentials and AYP measure in mathematics, reading and graduation rate as given by PSAE scores). This was provided by conducting the enter method of multiple linear regressions, correlation of variables, kurtosis and skewness, mean, variance, standard deviation, and p-value. These two variables interplayed as the secondary data retrieved online to validate the investigation about the correlation between school climate and achievement. In addition, the validity of the original secondary data that was retrieved for this study had been tested and refined over a period of over ten years where different replica data was gathered in different regions in the U.S. to inform policymakers about school climate and achievement (Bryk et al., 2010). To ensure consistency for each question in the survey, the research analyst checked whether respondents answered questions in a similar way or if they answered all questions in different ways.

The researcher took 1 week to collect two types of data: (1) the 5Essentials survey results for all 186 high schools from a low SES district in Midwestern U.S. This data was retrieved from the 5Essentials CCSR consortium's website at www. https://ccsr.uchicago.edu/school. (2) The AYP measure as given by schools PSAE scores in mathematics, reading and graduation rate available from https://illinoisreportcard.com/.The consortium's website where the permission is published, informed consent is not required from a researcher wishing to conduct research using this public data so long as he/she cite them as the source. They also do not need to submit any letter of intention to retrieve the data. (University of Chicago, 2013).

The original 5Essentials data was collected using survey instrument given annually to parent, teachers and students, the procedure involved participants taking survey online or using paper and pencil. This annual survey has been administered to all schools in this state for a period of over 10 years. But for the sake of this study only data for the years 2012 to 2014 was utilized.

To collect the second set of data, the researcher accessed public AYP data given by PSAE data for the study school district this datum was also a public data that require no informed consent. In the district where the study was conducted, PSAE exam was the end of year exam that was used to compute their AYP. To determine schools' AYPs, sub scores of this index were used, as required by NCLB (Applegate, 2008). Other than end of grade assessment scores on math and 


\section{International Journal of Social Science and Economic Research}

ISSN: $2455-8834$

Volume:06, Issue:01 "January 2021"

reading, $10 \%$ of the API was determined by dropout rates, graduation, and school attendance (Applegate, 2008).

Data retrieved here was high school interval color-coded scores for each of these 5Essentials: effective leaders, collaborative teachers, involved families, supportive environment and ambitious instructions. Then there was an aggregate score for the combined 5Essentials climate survey. The second set of data collected for all high school in the district under study was the APY measure, which was given by PSAE scores in mathematics reading and their graduation rate. Data were retrieved for the 2012 to 2014 school years and tabulated in a spreadsheet. Once the data were retrieved and tabulated in the spreadsheet, it was fed into the SPSS computation software for analysis.

The results of these tests were analyzed to reach conclusions that rejected the null hypothesis and confirm the notion fronted by the theory of action that schools with favorable school climate are 10 times more likely to perform better than those with unfavorable school climate. In addition, the results from data analysis were summarized, explained and reported using tables and graphs to show a correlational relationship between the variables and ranked the variables to show which had stronger correlation amongst them all.

\subsection{Ethical Considerations}

The study strictly followed the three principles of the Belmont report established in 1979 (DePoy\& Gitlin, 2015). According to DePoy and Gitlin (2015) the three principals include; respect for persona, beneficence, and justice. Appropriate parties were consulted for peer-review to resolve any doubts regarding ethical procedures or methods. To adhere to respect for persons, researchers and participants in the research complied with state and federal laws, and did not fabricate data. Ethical considerations for the conduct of the study, such as respect for privacy and safekeeping of the data, were adhered to always.

\section{Results and Discussions}

The data and results for each hypothesis were analyzed and discussed following the stated hypotheses or the research questions.

\subsection{Inferential analysis}

Table 1 shows that there was an observed difference between the mean score of five essentials and academic performance indicators (mathematic scores, reading scores and graduation rate) of low income high schools in Midwestern U.S. 
International Journal of Social Science and Economic Research

ISSN: 2455-8834

Volume:06, Issue:01 "January 2021"

Table 1: Comparing Sample Means between 2014 and 2013

Paired Samples Statisticsn=114.

\begin{tabular}{|c|c|c|c|c|c|}
\hline & & Mean & $\mathrm{N}$ & Std. Deviation & Std. Error Mean \\
\hline \multirow[t]{2}{*}{ Pair 1} & Math2013 & 28.57 & 114 & 25.342 & 2.374 \\
\hline & Math2014 & 28.91 & 114 & 25.180 & 2.358 \\
\hline \multirow[t]{2}{*}{ Pair 2} & English2013 & 31.70 & 114 & 23.236 & 2.176 \\
\hline & English2014 & 32.60 & 114 & 23.650 & 2.215 \\
\hline \multirow[t]{2}{*}{ Pair 3} & GraduationRate2013 & 79.14 & 114 & 25.994 & 2.435 \\
\hline & Graduationrate2014 & 72.05 & 114 & 35.277 & 3.304 \\
\hline \multirow[t]{2}{*}{ Pair 4} & MathEnglish2013 & 29.41 & 114 & 23.702 & 2.220 \\
\hline & MathEnglish2014 & 30.02 & 114 & 23.826 & 2.232 \\
\hline \multirow[t]{2}{*}{ Pair 5} & EL2013 & 48.31 & 114 & 18.414 & 1.725 \\
\hline & EL2014 & 50.51 & 114 & 18.960 & 1.776 \\
\hline \multirow[t]{2}{*}{ Pair 6} & СТ2013 & 50.26 & 114 & 18.598 & 1.742 \\
\hline & CT2014 & 56.32 & 114 & 19.382 & 1.815 \\
\hline \multirow[t]{2}{*}{ Pair 7} & IF2013 & 44.76 & 114 & 24.599 & 2.304 \\
\hline & IF2014 & 55.81 & 114 & 20.727 & 1.941 \\
\hline \multirow[t]{2}{*}{ Pair 8} & SE2013 & 48.00 & 114 & 19.933 & 1.867 \\
\hline & SE2014 & 52.32 & 114 & 18.211 & 1.706 \\
\hline \multirow[t]{2}{*}{ Pair 9} & AI2013 & 59.08 & 114 & 22.403 & 2.098 \\
\hline & AI2014 & 60.59 & 114 & 19.045 & 1.784 \\
\hline \multirow[t]{2}{*}{ Pair 10} & FiveEssentia2013 & 47.92 & 114 & 32.799 & 3.072 \\
\hline & FiveEssentials2014 & 57.82 & 114 & 32.583 & 3.052 \\
\hline
\end{tabular}

Table 1 shows comparison of the mean difference between two data sets collected in 2013 and in 2014 from the same sample frame of 114 schools $(\mathrm{df}=113)$

From Table 1, the average mean for 2014 was 50.51 and in 2013 the average/mean was 48.31 . Comparing the standard deviation for effective leadership, year 2013 had a standard deviation of 18.414 while that of 2014 increased to 18.96 standard deviations. Statistically, standard deviation explains how variables are distributed about the mean.

Table 1 furthershow that the mean for collaborative teachers in 2014 is 56.32 while in 2013 it was 50.26. This means that teachers have been increasingly partnering to aid student achievement. The standard deviation of collaborative teaching also improved from 18.598 in 2013 to 19.382 in 2014, which indicates that more teachers were collaborating. Data from this study show that in 2013, on average of 45 parents out of 100 were involved in their children's 


\section{International Journal of Social Science and Economic Research}

ISSN: $2455-8834$

Volume:06, Issue:01 "January 2021"

studies, while in 201456 parents out of 100 were involved. In 2013 standard deviation for parental involvement was 25, while in 2014 it dropped to 21 standard deviations indicating that involved families data was widely spread around the mean in 2013 (less reliable) than it was in 2014 (more reliable).

School climate element of supportive environment showed improvement between 2013 and 2014 as indicated in the Table 1. In 2014 with regard to supportive environment, the mean score was 52, which increased from a mean score of 48 in 2013. The standard deviation for this essential element was 20 in 2013 and 18 in 2014. In addition, Table 1 shows that there was an observed difference between ambitious instruction element of school climate means in 2013 and 2014. In 2014, ambitious instruction mean increased to 60.59 from 59.08 in 2013. This observed difference was also observed in standard deviation for ambitious instruction from 22.403 in 2013 to 19.045 in 2014. After describing differences in standard deviations and comparing the mean for both independent and dependent variables it followed data analysis using each hypothesis, to determine if the five independent variables are worth investing in. It was necessary to restate each null hypothesis followed by the results as they pertain to that null hypothesis.

\subsection{Hypotheses}

The first hypothesis was: There are no statistically significant relationships between the five essential components of organizational climate and AYP in mathematics in low SES high schools in Midwestern U.S. The mean score for mathematics improved from 28.57 in 2013 to 28.91 in 2014 which is a negligible increase of only 0.34 units. This observed deference is seen to be an element of chance because the standard deviation reduced by 0.162 units for those two years. This is an indication that in absolute values the five essential components (effective leaders, collaborative teachers, parental involvement, supportive environment and ambitious instructions) do not explain mathematical scores strongly as indicated from the descriptive analysis. Looking at the mean differences there is no statistically significant relationship between school climate and mathematics achievement. Thereby according to descriptive statistics, the study accepted the null hypothesis and rejecting alternative hypothesis that school climate affects student achievement in mathematics. Since the assumptions of statistical data were not yet tested at this stage of the study, there was no statistical test conducted in this section other than means comparison. Thus, after observing the mean difference and standard deviations from 2013 to 2014 and accepting the null hypotheses, there was a need for further statistical tests and analysis to show whether there was an incorrect retention of the null hypothesis. This need prompted further test using ANOVA and correlation of variables. However before conducting statistical parametric procedures, normality test and other typical assumptions for statistical tests were tested. 


\section{International Journal of Social Science and Economic Research}

ISSN: $2455-8834$

Volume:06, Issue:01 "January 2021"

The second hypothesis was: H20: There are no statistically significant relationships between the five essential components of organizational climate and AYP in reading in low SES high schools in Midwestern U.S. Table 1 shows mean comparison for reading score for year 2014and 2013. In 2014, the reading scores were observed to have improved to 32.6 from 31.7 in 2013 . This was a marginal improvement by 0.9-unit improvement of scores around the mean. Similarly, a marginal improvement in reading score standard deviation was observed from 23.25 in 2013 to 23.236 in 2014 which is 0.414 improvements. These results indicate that the five essential components (effective leaders, collaborative teachers, parental involvement, supportive environment and ambitious instructions) have an impact on reading score. Therefore, using mean comparison, school climate has a statistically significant impact on student achievement in reading.

The third hypothesis was: H30: There are no statistically significant relationships between the five essential components of organizational climate and graduation rate in low SES high schools in Midwestern U.S. In 2013 the graduation rate mean was 79.14\% while in 2014 the graduation rate decreased to 72.05 this was seven percent decrease in one year. This decrease was a an element of chance or subject of bias because it was affirmed and explained further by the standard deviation widening from 25.994 in 2013 to 35.277 in 2014 a 9.283 standard deviations increase in one year. This is an indication that the improvement in graduation cannot be explained by the five essential components of organizational climate (effective leaders, collaborative teachers, parental involvement, supportive environment and ambitious instructions) using descriptive statistics. Following these mean comparisons, there were no statistically significant relationships between school climate and graduation rate, therefore the better school climate does not result in higher graduation rates, for this sample. Following this inconclusive comparison of means, further test using ANOVA and correlation of variables was conducted.

\subsection{AYP mathematical analysis}

This study sought to find out the extent to which the five essential components (effective leadership, collaborative teachers, parental involvement, supportive environment and ambitious instructions) of organizational climate explain mathematical scores in low SES high schools in Midwestern U.S. Using SPSS analysis, this study found out that the five essential components (effective leadership, collaborative teachers, parental involvement, supportive environment and ambitious instructions) explains $59.4 \%$ in 2013 and $39.5 \%$ in 2014 of the AYP, PSAE mathematics scores in low SES high schools in Midwestern U.S. as show in Table 2. Each research question was regressed against the five predictors to identify if there was a correlation and to which extent that correlation explains the dependent variable. The analysis followed restating of each research question. 


\section{International Journal of Social Science and Economic Research}

ISSN: $2455-8834$

Volume:06, Issue:01 "January 2021"

The first research question was: R1: To what extent are the five essential components of organizational climate related to AYP in mathematics in low SES high schools in Midwestern U.S.? For Research question 1, Table 2 indicates the results of the linear regression analysis of the correlation (R), variation on dependent variable, (R-Squared). Further analysis (Table 2) indicated coefficients of AYPs in mathematics correlated against each of the 5Essential components of school climate. This correlation showed effect of unit investment on each of the 5Essential components to mathematics achievement.

Table 2: Model Summary for AYP, PSAE Mathematics scores n=114

\begin{tabular}{lcccc}
\hline Model & $R$ & $R$ Square & Adjusted $R$ Square & Std. Error of the Estimate \\
\hline 2013 & .770 & .594 & .571 & 16.601 \\
2014 & .628 & .395 & .361 & 11.622 \\
\hline
\end{tabular}

Note. Predictors: (Constant), Ambitious Instructions, Parental Involvement, Collaborative Teachers, Effective Leadership, Supportive Environment

Table 2 shows the $\mathrm{R}$ and $R^{2}$ for the five essential components of organizational climate related to AYP, PSAE in mathematics in low SES high schools in Midwestern U.S. The $R$ value represents the simple correlation of 0.53 as shown on the R column, which indicates a moderate degree of correlation between the five essential components and AYP, PSAE scores in mathematics in low SES high schools in Midwestern U.S. The $R^{2}$ value as shown on the R-Square column indicates how much of the total variation in the dependent variable, mathematic performance, is explained by the independent variable, the five essential components. In this case $59.4 \%$ in 2013 and $39.5 \%$ in 2014 of performance in mathematics is explained five school climate's essential elements of, ambitious instructions, parental involvement, collaborative teachers, effective leadership and supportive environment. This study further sought to quantify the level at which each of the five essential variables explains AYP of PSAE in mathematics in low SES high schools in Midwestern U.S. for both 2013 and 2014.

Table 3: ANOVA ${ }^{\text {a }}$ for mathematics $2013 n=114$

\begin{tabular}{lccccc}
\hline Model & Sum of Squares & df & Mean Square & F & Sig. \\
\hline Regression & 43082.486 & 6 & 7180.414 & 26.054 & $.000^{\mathrm{b}}$ \\
Residual & 29489.453 & 107 & 275.602 & & \\
Total & 72571.939 & 113 & & & \\
\hline
\end{tabular}

a. Dependent Variable: Math2013

b. Predictors: (Constant), FiveEssentia2013, EL2013, IF2013, AI2013, CT2013, SE2013 
International Journal of Social Science and Economic Research

ISSN: 2455-8834

Volume:06, Issue:01 "January 2021"

RQ1: A multiple regression was run to predict AYP in mathematics for 2013 from effective leadership, collaborative teachers, parental involvement, supportive environment and ambitious instructions. Only parental involvement and supportive environment statistically predicted the AYP in mathematics. Table 3 indicate that these variables statistically significantly predicted AYP in mathematics, $F(6,107)=26.054, p<.05, R^{2}=.594$. Only two out of five variables added statistically significantly to the prediction, $p<.05$.

Table 4: ANOVA a for mathematics $2014 \mathrm{n}=114$

\begin{tabular}{lccccc}
\hline & Sum of Squares & df & Mean Square & F & Sig. \\
\hline Regression & 43082.486 & 6 & 7180.414 & 26.054 & $.000^{\mathrm{b}}$ \\
Residual & 29489.453 & 107 & 275.602 & & \\
Total & 72571.939 & 113 & & & \\
\hline
\end{tabular}

a. Dependent Variable: Math2013

b. Predictors: (Constant), FiveEssentia2013, EL2013, IF2013, AI2013, CT2013, SE2013

Similarly a multiple regression was run to predict AYP in mathematics from effective leadership, collaborative teachers, parental involvement, supportive environment and ambitious instructions for 2014. Only parental involvement and supportive environment statistically predicted the AYP in mathematics. Table 4 indicate that these variables statistically significantly predicted AYP in mathematics, $F(6,107)=11.622, p<.05, R^{2}=.577$. Only two out of five variables added statistically significantly to the prediction, $p<.05$.

Table 5: Coefficients for AYP in Mathematics 2013-2014 $(n=114)$

\begin{tabular}{lcccccc}
\hline & \multicolumn{2}{c}{$\begin{array}{c}\text { Unstandardized } \\
\text { Coefficients }\end{array}$} & \multicolumn{2}{c}{$\begin{array}{c}\text { Standardized } \\
\text { Coefficients }\end{array}$} & & \\
\cline { 2 - 4 } Model & $B$ & Std. Error & Beta & & Sig. \\
\hline (Constant) & -2.266 & 5.925 & & -.382 & .703 \\
& -15.169 & 8.577 & & -2.067 & $.041^{*}$ \\
Effective Leadership & -.117 & .144 & -.085 & -.812 & .419 \\
& .077 & .157 & .058 & .488 & .627 \\
Collaborative Teachers & -.296 & .157 & -.217 & -1.885 & .062 \\
& -.532 & .187 & -409 & -2.842 & $.005^{*}$ \\
Parental Involvement & .656 & .108 & .637 & 6.087 & $.000^{*}$ \\
& .731 & .146 & .602 & 5.007 & $.000^{*}$
\end{tabular}




\section{International Journal of Social Science and Economic Research}

ISSN: $2455-8834$

Volume:06, Issue:01 "January 2021"

\begin{tabular}{lccccc}
- & .577 & .213 & .454 & 2.716 & $.008^{*}$ \\
& .483 & .187 & .349 & 2.580 & $.011^{*}$ \\
Ambitious Instruction 2013 & -.096 & .186 & -085 & -.520 & .604 \\
2014 & .068 & .174 & .051 & .389 & .698 \\
\hline
\end{tabular}

Note. a. Dependent Variable: Mathematics scores

* significant at the $p<0.05$ level

From Table 5, the study found out that holding all variables constant in 2013, on average a student would score -2.266 points in mathematics. Additionally, a unit investment in effective leadership would result in a decrease of -0.117 in mathematics scores, which is not significant as shown by a $p$-value of 0.419 , as is more than the benchmark $p$-value of 0.05 . This study further found out that a unit investment in collaborative teaching would decrease mathematic performance by 0.296 units, which is not significant as shown by a $p$-value of 0.419 , which is more than the benchmark $p$-value of 0.05 .

The study also found out that a unit investment in parental involvement results to 0.656 units increase in mathematics score, which is significant as shown by a $p$-value of 0.000 , which is less than the benchmark $p$-value of 0.05 . The study found out that supportive environment has a positive impact on mathematical involvement where a unit investment in supportive environment results to an increase of mathematical score by 0.577 , which is significant as shown by a $p$-value of 0.008 which is less than the statistical $p$-value of 0.05 . In addition, this study found out that a unit investment in ambitious instruction results in a 0.997 unit decrease in mathematical scores, which is insignificant as shown by a $p$-value of 0.604 which is more than the statistical benchmark of $0.05 p$-values.

For the year 2014, the study found out that holding all variables constant, on average a student would score -15.167 points in mathematics. However, a unit investment in effective leadership would result in 0.077 improvements in mathematic score. This improvement is not significant as shown by a $p$-value of 0.627 , which is more than the benchmark $p$-value of 0.05 . This study further found out that a unit investment in collaborative teaching would decrease mathematic performance by 0.532 units, which is significant as shown by a $p$-value of 0.005 . This is less than the benchmark $p$-value of 0.05 . The study also found out that a unit investment in parental involvement results in 0.731 units increase in mathematics score, which is significant as shown by a $p$-value of 0.000 which is less than the benchmark $p$-value of 0.05 . The study found out that supportive environment has a positive impact on mathematical involvement where a unit investment in supportive environment results to an increase of mathematical score by 0.483 , which is significant as shown by a $p$-value of 0.011 . This is less than the statistical $p$-value of 0.05. In addition, this study found out that a unit investment in ambitious instruction results to 


\section{International Journal of Social Science and Economic Research}

ISSN: $2455-8834$

Volume:06, Issue:01 "January 2021"

0.068 units decrease in mathematical score, which is insignificant as shown by a $p$-value of 0.698 which is more than the statistical benchmark of $0.05 p$-values.

As seen in the Pearson correlation, the strongest predictor for achievement improvement in mathematics in 2013 was parental involvement followed by supportive environment, ambitious instruction collaborative teachers, and effective leaders in that order. From Table 5, the study estimated that the linear regression model for mathematics to be explained by the five essentials to be: AYP mathematics $=-2.266-0.117$ (Effective Leadership) -0.296 (Collaborative Teachers) + 0.656 (Parental Involvement) + 0.577 (Supportive Environment) - 0.096 (Ambitious Instructions). From these findings the study shows that out of the five essentials only two had positive coefficients and significant levels of $p<0.05$ (parental involvement and supportive environment). Although this study accepts the null hypothesis and rejects the alternative hypothesis that there are statistically significant relationships between the five essential components of organizational climate and AYP, PSAE scores in mathematics in low SES high schools in Midwestern U.S., it should be noted that some of the five essentials contributed positively to increase in mathematics scores (parental involvement and supportive environment). Overall statistics shown on table 5 shows that effective leadership, collaborative teachers and ambitious instructions are the three out of five elements of school climate that had negative effect on AYP, PSAE scores in mathematics. To ascertain causes of these negative coefficients and insignificancies, future studied should investigate these correlations further.

\subsection{AYP reading scores analysis}

The second research question was: R2: To what extent are the five essential components of organizational climate related to AYP in reading in low SES high schools in Midwestern U.S.? For Research Question 2, this study sought to determine the extent to which the five essential components (effective leadership, collaborative teachers, parental involvement, supportive environment and ambitious instructions) of organizational climate related to AYP, PSAE in reading in low SES high schools in Midwestern U.S.

Table 6: Model Summary for AYP Reading $n=114$

\begin{tabular}{lcccc}
\hline Model & $R$ & $R$ Square & Adjusted $R$ Square & Std. Error of the Estimate \\
\hline 2013 & .728 & .530 & .504 & 16.368 \\
2014 & .637 & .406 & .373 & 18.733
\end{tabular}

Note. Predictors: (Constant), Ambitious Instructions, Parental Involvement, Collaborative Teachers, Effective Leadership, Supportive Environment. 


\section{International Journal of Social Science and Economic Research}

ISSN: $2455-8834$

Volume:06, Issue:01 "January 2021"

Table 6 shows the $\mathrm{R}$ and $R^{2}$ for the five essential components of organizational climate related to AYP, PSAE in reading in low SES high schools in Midwestern U.S. The $R$ value represents an average correlation of 0.728 in 2013 and .637 in 2014 as shown on the R column. This indicates a correlation exist between the five essential components and AYP, PSAE in reading in low SES high schools in Midwestern U.S. The $R^{2}$ value as shown on the R-Square column indicates how much of the total variation in the dependent variable, reading, is explained by the independent variable, the five essential components.In this case 53\% in 2013 and $40.6 \%$ in 2014 of reading scores are explained by the five essentials of: ambitious instructions, parental involvement, collaborative teachers, effective leadership and supportive environment.

This study further sought to explain the extent to which each of the five essential components of organizational climate related to AYP, PSAE in reading in low SES high schools in Midwestern U.S. As shown in Table 6, the study found out that holding all variables constant on average a student would score 14.5 in 2013, showing a decrease of 2.655 in 2014 points in reading. In 2013, a unit investment in effective leadership would result in a 0.136 decrease in reading score. This decrease is not significant as shown by a $p$-value of 0.352 , which is more than the benchmark $p$-value of 0.05 . This study further found out that a unit investment in collaborative teaching would decrease reading performance by 0.405 units, which is significant as shown by a $p$-value of 0.012 . This value is more than the benchmark $p$-value of 0.05 . Further analysis in the study found out that a unit investment in parental involvement results in 0.639 units increase in reading score, which is significant as shown by a $p$-value of 0.000 . This is less than the benchmark $p$-value of 0.5 . The study also found out that a unit investment in supportive environment results to 0.014 unit's decrease, which is not significant as shown by a $p$-value of 0.947. This is more than the statistical $p$-value of 0.05 . In addition, this study found out that a unit investment in ambitious instruction results to 0.133 units increase in mathematical score, which is significant as shown by a $p$-value of 0.000 which is less than the statistical benchmark of $0.05 p$-values.

In 2014, a unit investment in effective leadership would result in a 2.655 decrease in reading score. This decrease is significant as shown by a $p$-value of 0.046 which is less than the benchmark $p$-value of 0.05 . This study further found out that a unit investment in collaborative teaching would decrease reading performance by 0.696 , units which is significant as shown by a $p$-value of 0.012 a value less than the benchmark $p$-value of 0.05 . Further analysis in the study found out that a unit investment in parental involvement results to 0.843 units increase in reading score, which is significant as shown by a $p$-value of 0.000 which is less than the benchmark $p$ value of 0.5 . The study also found out that a unit investment in supportive environment results to 0.133 unit's improvement which is significant as shown by a $p$-value of 0.007 which is less than the statistical $p$-value of 0.05 . In addition, this study found out that a unit investment in 
International Journal of Social Science and Economic Research

ISSN: 2455-8834

Volume:06, Issue:01 "January 2021"

ambitious instruction results in 0.013 units decrease in reading score which is not significant as shown by a $p$-value of 0.943 which is less than the statistical benchmark of $0.05 p$-values.

Table 7: ANOVA $^{\text {a }}$ Reading 2013 n=114

\begin{tabular}{lccccc}
\hline Model & Sum of Squares & df & Mean Square & F & Sig. \\
\hline Regression & 32341.418 & 6 & 5390.236 & 20.120 & $.000^{\mathrm{b}}$ \\
Residual & 28666.441 & 107 & 267.911 & & \\
Total & 61007.860 & 113 & & & \\
\hline
\end{tabular}

a. Dependent Variable: English2013

b. Predictors: (Constant), FiveEssentia2013, EL2013, IF2013, AI2013, CT2013, SE2013

RQ2: A multiple regression was run to predict AYP in reading for 2013 from effective leadership, collaborative teachers, parental involvement, supportive environment and ambitious instructions. Only parental involvement, supportive environment and ambitious instruction statistically predicted the AYP in reading. Table 7 indicate that these variables statistically significantly predicted AYP in reading, $F(6,107)=20.120, p<.05, R^{2}=.637$. Only three out of five variables added statistically significantly to the prediction, $p<.05$.

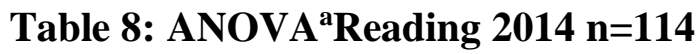

\begin{tabular}{lccccc}
\hline Model & Sum of Squares & $d f$ & Mean Square & $F$ & Sig. \\
\hline Regression & 25657.857 & 6 & 4276.310 & 12.186 & $.000^{\mathrm{b}}$ \\
Residual & 37547.581 & 107 & 350.912 & & \\
Total & 63205.439 & 113 & & & \\
\hline
\end{tabular}

a. Dependent Variable: English2014

b. Predictors: (Constant), FiveEssentials2014, EL2014, SE2014, IF2014, CT2014, AI2014

Similarly, multiple regressions were run to predict AYP in reading for 2014 from effective leadership, collaborative teachers, parental involvement, supportive environment and ambitious instructions. Only parental involvement, supportive environment, and ambitious instruction statistically predicted the AYP in reading. Table 8 indicate that these variables statistically significantly predicted AYP in reading, $F(6,107)=12.186, p<.05, R^{2}=.728$. Only three out of five variables added statistically significantly to the prediction, $p<.05$. 
International Journal of Social Science and Economic Research

ISSN: 2455-8834

Volume:06, Issue:01 "January 2021"

Table 9: Coefficients for AYP in Reading Scores for 2013-2014 ( $n=114)$

\begin{tabular}{|c|c|c|c|c|c|}
\hline \multirow[b]{2}{*}{ Model } & \multicolumn{2}{|c|}{ Unstandardized Coefficients } & \multirow{2}{*}{$\begin{array}{c}\begin{array}{c}\text { Standardized } \\
\text { Coefficients }\end{array} \\
\text { Beta }\end{array}$} & \multirow[b]{2}{*}{$T$} & \multirow[b]{2}{*}{ Sig. } \\
\hline & $B$ & Std. Error & & & \\
\hline \multirow[t]{2}{*}{ (Constant) } & 14.524 & 7.202 & & 2.017 & $.046^{*}$ \\
\hline & -2.655 & 7.980 & & -.333 & .740 \\
\hline \multirow[t]{2}{*}{ Effective Leadership } & -.136 & .145 & -.107 & -.936 & .352 \\
\hline & .086 & .146 & .069 & .589 & .557 \\
\hline \multirow[t]{2}{*}{ Collaborative Teachers } & -.405 & .158 & -.324 & -2.558 & $.012^{*}$ \\
\hline & -.696 & .181 & -.571 & -3.843 & $.000^{*}$ \\
\hline \multirow{2}{*}{ Parental Involvement } & .639 & .108 & .676 & 5.927 & $.000^{*}$ \\
\hline & .842 & .140 & .738 & 6.006 & $.000 *$ \\
\hline \multirow[t]{2}{*}{ Supportive Environment } & -.014 & .219 & -.012 & -.066 & .947 \\
\hline & .478 & .175 & .368 & 2.733 & $.007^{*}$ \\
\hline \multirow[t]{2}{*}{ Ambitious Instructions } & .133 & .186 & .129 & .717 & $.000 *$ \\
\hline & -.013 & .185 & -.011 & -.071 & .943 \\
\hline
\end{tabular}

Note. Dependent Variable: Reading scores

* significant at the $p<0.05$ level

From Table 9 it can be deduced that the linear regression equation of reading as explained by the five essential components is: AYP Reading $2013=14.524$; (Effective Leadership) $=-0.136$; (Collaborative Teachers) -0.405; (Parental Involvement) - +.639; (Supportive Environment) 0.014 and (Ambitious instructions) -+.133 . Similarly, AYP Reading $2014=-2.655 ;+0.086=$ (Effective Leadership); - 0.696 (Collaborative Teachers); + 0.842 (Parental Involvement); + $0.478=$ (Supportive Environment) and - 0.013 (Ambitious instructions).

From this analysis the study found that all the five essential of organizational climate related to AYP, PSAE in reading in low SES high schools in Midwestern U.S. are significant except effective leadership. However, on averaging the coefficient for 2013 and 2014, this study found that effective leadership and collaborative teachers had significantly negative correlation coefficients and did not improve students' achievement. On the other hand, parental involvement, supportive environment, and ambitious instructions were the factors that had positive average coefficients and significance level of $p<0.05$ for both years. It can be seen from Table 9 that the strongest predictor for achievement improvement in reading are parental 


\section{International Journal of Social Science and Economic Research}

ISSN: $2455-8834$

Volume:06, Issue:01 "January 2021"

involvement, followed by supportive environment and ambitious instructions. This study therefore accepts the null hypothesis and rejects the alternative hypothesis that, there are some statistically significant relationships between the five essential components of organizational climate and AYP, PSAE in reading scores in low SES high schools in Midwestern U.S. It is important to note here that not all the five essentials of school climate had positive correlations that were significant. Effective leadership had negative effect on student achievement and collaborative teachers were significantly negative coefficients. Therefore, parental involvement, supportive environment and ambitious instructions were the three out of five essential elements that had positive significant effect on students' achievement on reading. Looking at data from both 2013 and 2014 data parental involvement was the most significant predictor for both reading and math achievements. It is therefore one of the five essentials of organizational climate that had the greatest impact on both math and reading AYP scores. Following closely in significance relationship of variables was supportive environment and ambitious instruction. Effective school leadership and collaborative teachers were not found to be significant at all in affecting students' academic achievement in both math and reading.

\subsection{Graduation rate}

The third research question was: R3: To what extent are the five essential components of organizational climate related to graduation rate in low SES high schools in Midwestern U.S.? For Research Question 3, the correlation analysis conducted by SPSS-10® sought to find out the extent to which the five essential components (effective leadership, collaborative teachers, parental involvement, supportive environment and ambitious instructions) of organizational climate are related to graduation rate in low SES high schools in Midwestern U.S.

Table 10: Model Summary for Graduation Rate n=114

\begin{tabular}{lcccc}
\hline Model & $R$ & $R$-Square & Adjusted $R$ Square & Std. Error of the Estimate \\
\hline 2013 & .081 & .007 & -.039 & 26.501 \\
2014 & .383 & .146 & .098 & 33.495
\end{tabular}

Note. Predictors: (Constant), Ambitious Instructions, Parental Involvement, Collaborative Teachers, Effective Leadership, Supportive Environment.

Table 10 shows the $\mathrm{R}$ and $R^{2}$ for the five essential components of organizational climate related to graduation rate in low SES high schools in Midwestern U.S. The $R$ value represents the simple correlation of 0.081 in 2013 and 0.383 in 2014 as shown on the R-column. This indicated a moderate degree of correlation between the five essential components and graduation rate in low 


\section{International Journal of Social Science and Economic Research}

ISSN: $2455-8834$

Volume:06, Issue:01 "January 2021"

SES high schools in Midwestern U.S. The $R^{2}$ value as shown on the R-Square column indicates how much of the total variation in the dependent variable, graduation rate, is explained by the independent variable, the five essential components. In this case $7.0 \%$ and $14.6 \%$ of graduation rate was explained by ambitious instructions, parental involvement, collaborative teachers, effective leadership and supportive environment in 2013 and 2014 respectively.

Further, this study sought to explain the extent to which each of the five essential components of organizational climate were related to graduation rate in low SES high schools in Midwestern U.S. The study found out that in 2013, holding all variables constant, on average, 78 students would graduate from high school. However, a unit investment in effective leadership would result to .031 units decrease in graduation rate. This improvement is significant as shown by a $p$ value of 0.00 which is less than the benchmark $p$-value of 0.05 . This study further found out that a unit investment in collaborative teaching would decrease graduation rate by 0.005 units, which is not significant as shown by a $p$-value of 0.983 , which is more than the benchmark $p$-value of 0.05 . The study further found out that a unit investment in parental involvement results to 0.075 units decrease in graduation rate which is not significant as shown by a p-value of 0.000 which is more than the benchmark $p$-value of 0.5 . The study also found out that a unit investment in supportive environment results to 0.082-unit improvement which is not significant as shown by a $p$-value of 0.810 which is more than the statistical $p$-value of 0.05 . In addition, this study found out that a unit investment in ambitious instruction results to 0.035 units increase in graduation rate which is significant as shown by a $p$-value of 0.026 which is less than the statistical benchmark $p$-value of 0.05 .

Table 11: ANOVA ${ }^{a}$ for Graduation Rate2013 n=114

\begin{tabular}{lccccc}
\hline Model & Sum of Squares & Df & Mean Square & F & Sig. \\
\hline Regression & 2104.587 & 6 & 350.764 & .505 & $.803^{\text {b }}$ \\
Residual & 74249.168 & 107 & 693.917 & & \\
Total & 76353.754 & 113 & & & \\
\hline
\end{tabular}

a. Dependent Variable: GraduationRate2013

b. Predictors: (Constant), FiveEssentia2013, EL2013, IF2013, AI2013, CT2013, SE2013

RQ3: A multiple regression was run to predict AYP in graduation rate 2013 from effective leadership, collaborative teachers, parental involvement, supportive environment and ambitious instructions. Only supportive environment statistically predicted the AYP in graduation rate. From table 11 these variables statistically significantly predicted AYP in graduation rate, $F$ (6, $107)=0.505, p<.05, R^{2}=.0 .007$ Only one out of five variables added statistically significantly to the prediction, $p<.05$. 
International Journal of Social Science and Economic Research

ISSN: 2455-8834

Volume:06, Issue:01 "January 2021"

Table 12: ANOVA ${ }^{\mathrm{a}}$ for Graduation Rate 2014 n=114

\begin{tabular}{lccccc}
\hline Model & Sum of Squares & $d f$ & Mean Square & $F$ & Sig. \\
\hline Regression & 20579.75 & 6 & 3429.959 & 3.057 & $.008^{\mathrm{b}}$ \\
Residual & 120043.929 & 107 & 1121.906 & & \\
Total & 140623.684 & 113 & & & \\
\hline
\end{tabular}

a. Dependent Variable: Graduationrate2014

b. Predictors: (Constant), FiveEssentials2014, EL2014, SE2014, IF2014, CT2014, AI2014

Similarly, multiple regression was run to predict AYP in graduation rate for 2014 from effective leadership, collaborative teachers, parental involvement, supportive environment and ambitious instructions. Only supportive environment statistically predicted the AYP in graduation rate. Table 12 indicate that these variables statistically significantly predicted AYP in graduation rate, $F(6,107)=3.057, p<.05, R^{2}=.146$. Only one out of five variables added statistically significantly to the prediction, $p<.05$.

\section{Table 13Coefficients for Graduation Rate (2013-2014) n=114}

\begin{tabular}{|c|c|c|c|c|c|}
\hline \multirow[b]{2}{*}{ Model } & \multicolumn{2}{|c|}{ Unstandardized Coefficients } & \multirow{2}{*}{$\begin{array}{c}\begin{array}{c}\text { Standardized } \\
\text { Coefficients }\end{array} \\
\text { Beta }\end{array}$} & \multirow[b]{2}{*}{$T$} & \multirow[b]{2}{*}{ Sig. } \\
\hline & $B$ & Std. Error & & & \\
\hline \multirow[t]{2}{*}{ (Constant) } & 78.303 & 9.439 & & 8.295 & $.000^{*}$ \\
\hline & 102.140 & 14.268 & & 7.159 & $.000^{*}$ \\
\hline \multirow[t]{2}{*}{ Effective Leadership } & -.031 & .230 & -.022 & -.136 & .892 \\
\hline & .510 & .262 & .274 & 1.947 & .053 \\
\hline \multirow[t]{2}{*}{ Collaborative Teachers } & -.005 & .250 & -.004 & -.021 & .983 \\
\hline & -.712 & .324 & -.391 & -2.197 & $.023 *$ \\
\hline \multirow[t]{2}{*}{ Parental Involvement } & -.075 & .172 & -.071 & -.439 & .661 \\
\hline & .315 & .251 & .187 & 1.267 & .197 \\
\hline \multirow[t]{2}{*}{ Supportive Environment } & .082 & .339 & .063 & .241 & .810 \\
\hline & .119 & .312 & .062 & .382 & .700 \\
\hline \multirow[t]{2}{*}{ Ambitious Instructions } & .035 & .296 & .030 & .119 & .906 \\
\hline & -.655 & .330 & -.350 & -1.965 & $.026^{*}$ \\
\hline
\end{tabular}

Note. Dependent Variable: Graduation Rate

* significant at the $p<0.05$ level 


\section{International Journal of Social Science and Economic Research}

ISSN: $2455-8834$

Volume:06, Issue:01 "January 2021"

From Table 13 the linear regression SPSS equation of graduation rate as explained by the five essential components was: AYP Reading $2013=78.303-0.031$ (Effective Leadership) - 0.005 (Collaborative Teachers) - 0.075(Parental Involvement) + 0.082 (Supportive Environment) + 0.035 (Ambitious Instructions). In addition, AYP Reading $2014=102.140+0.510$ (Effective Leadership) - 0.712 (Collaborative Teachers) +315(Parental Involvement) + 0.119 (Supportive Environment) - 0.665 (Ambitious Instructions).

From this analysis, the study found all five essentials except collaborative teachers 2014 (significant but with negative correlation) and ambitious instruction 2014 significant but negative correlation in relation to graduation rate in low SES high schools in Midwestern U.S. are not significant. However, on averaging the correlation coefficients for both 2013 and 2014, supportive environment, parental involvement and effective leader had positive effect on graduation rate although they were not significant. Since some correlation coefficients were positive but not significant at $p<0.05$, it was not possible to make conclusion based on data provided on table 14. Therefore, to make conclusions about the correlations of the five essentials and graduation rate this study utilized Pearson correlation matrix given on table 14. It can also be seen from Table14 that using the, Pearson correlation the strongest predictor for graduation rate was supportive environment, followed by, ambitious instruction, parental involvement, collaborative teachers, and effective leaders in that order. This study; therefore, accepts the third null hypothesis and rejects its alternative hypothesis that, there are positive correlations between the five essential components of organizational climate and graduation rate in low SES high schools in Midwestern U.S. However, it should be noted here that the only factor that had positive average correlations for 2013 and 2014 were supportive environment, parental involvement and effective leader as given by table 13. Based on both correlation coefficient table 13 results and Pearson correlation matric table 14 it can be deduced that, unlike the effect and significance of the five essentials in relation to math and reading scores, graduation rate was significantly influenced by supportive environment which had the strongest correlation and the only element that was significant at $p<0.05$. Ambitious instruction and effective leadership has some significance though not as strong as supportive environment. Although the average effect of parental involvement was not very significant to graduation rate, it had a mild effect on AYP score given by graduation rate in the district under study. Among the three dependent variables, parental involvement was the strongest predictor that had significant effect on the achievement levels of all the three variables. Effective leadership and collaborative teachers were found to have insignificant effect on all the three dependent variables. Consequently, all the three null hypothesis were accepted but with a note that not all the five essentials of school climate correlated significantly with AYP, PSAE scores. Mathematics scores were significantly correlated with parental involvement and supportive environment, reading was significantly correlated with parental involvement, supportive environment and ambitious instructions. 


\section{International Journal of Social Science and Economic Research}

ISSN: $2455-8834$

Volume:06, Issue:01 "January 2021"

Graduation rate on the other hand was correlated with supportive environment (positive significant), parental involvement, ambitious instruction and effective leadership in that order.

\subsection{Correlation matrix for independent variables and dependent variables}

Both descriptive and inferential statistics from SPSS-10® pointed towards rejecting the alternative hypotheses and accepts the null hypotheses. However, using descriptive statistical analysis, the statistical significance of the five essentials and achievement in mathematics was considered low. Although some statistical significance was revealed between these two sets of variables, further analysis using inferential analysis and correlation matrix below (Table 14) indicated otherwise which implies that practical significance of the comparison of means can be contended. The supports for accepting the null hypotheses are supported by the analysis of correlation matrix (Table 14) after rejecting the three alternative hypotheses restated below.

$\mathrm{H} 1_{\mathrm{A}}$ : There are statistically significant relationships between the five essential components of organizational climate and AYP in mathematics in low SES high schools in Midwestern U.S.

$\mathrm{H} 2_{\mathrm{A}}$ : There are statistically significant relationships between the five essentialcomponents of organizational climate and AYP in reading in low SES high schools in Midwestern U.S.

$\mathrm{H} 3_{\mathrm{A}}$ : There are statistically significant relationships between the five essentialcomponents of organizational climate and graduation rate in low SES high schools in Midwestern U.S.

After conducting the inferential statistics and finding out that the study should accept all three null hypotheses and reject the alternative hypotheses it was noted that some of the five essentials had no significance or/and had negative correlation coefficients. Thus, in order to make the results more valid and reliable, this study sought to find out further relationship between the independent and dependent variables. This was to be established by conducting a two-tailed correlation as shown in the matrix Table 14. The statistical test used to determine if correlation existed and to find out the significance levels of the variables was Pearson's correlations coefficient calculator. From the research findings accepting the null hypothes is based on their significance level is supported by correlation matrix in table 14. It is evident from the matrix that the five essential components of school climate (effective leader, ambitious instruction, collaborative teachers, supportive environment and involved families) are significant predictors of two of three dependent variables (mathematics scores and reading scores). For graduation rate correlation coefficient table 13 showed average positive correlations for supportive environment, effective leadership and parental involvement but not for ambitious instruction and collaborative teachers.

In addition, the two-tailed correlation matrix showed that only supportive environment and ambitious instruction were significant at $p<0.05$. This points to a conclusion that supportive 


\section{International Journal of Social Science and Economic Research}

ISSN: $2455-8834$

Volume:06, Issue:01 "January 2021"

environment was the single element out of the five essentials that that greatly affect graduation rate. It was conclusive that some of the five essentials had negative effect on student achievement. In mathematics, parental involvement and supportive environment were the elements that accounted for the score increase. In reading, parental involvement, supportive environment and ambitious instructions were the three out of five essential components of school climate that explained positive increase in scores. For graduation rate, supportive environment was the greatest factor that explained the number of students who graduated within 2013 and 2014 school years.

However, it is important to note that this study did not go in to detail to determine if each dependent variable by itself can predict the other dependent variables therefore future studies could explore this option.

Table 14: Correlation Matrix between the Independent and Dependent Variables n=114

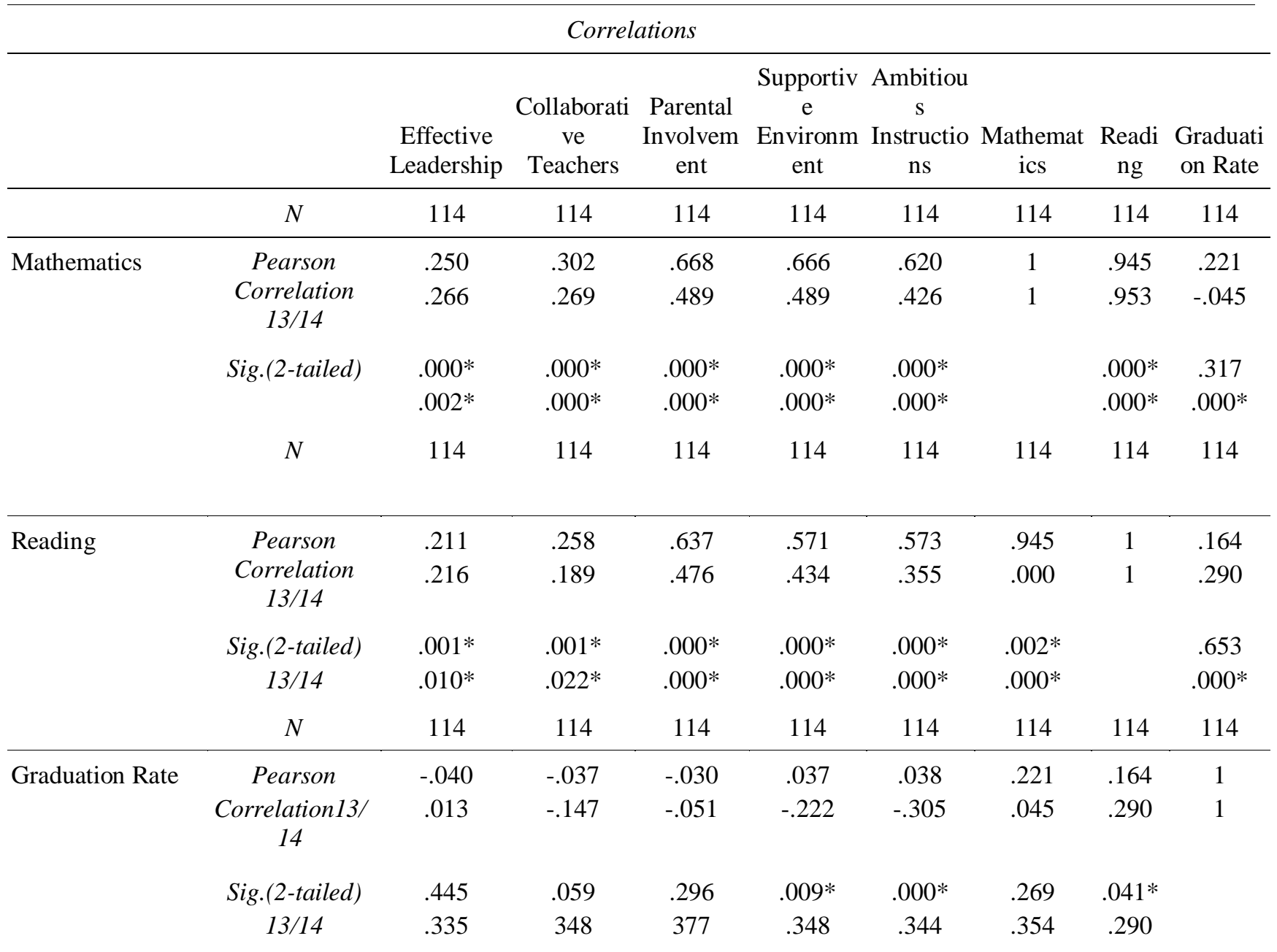


International Journal of Social Science and Economic Research

ISSN: 2455-8834

Volume:06, Issue:01 "January 2021"

$\mathrm{N}$

114

114

114

114

114

114

114

114

Note. *Correlation is significant at the $p<0.05$ level (2-tailed).

\section{Conclusions and Recommendations}

The correlation matrix results for this study shown in Table 14 are in line with Augustine-Shaw (2015) study which noted that leadership and learning are highly correlated with identifying an effective design for mentoring new building leaders because mentoring offers the new learner an environment for mastering and understanding the practical world. This ratifies the importance of investment on the five essential components of organization climate on performance at high school level because besides academic achievement learners at high school level are also involved in students' employment opportunities outside school environment. In such work settings, students work with mentors who help and model to them roles and duties of effective leaders.

This study was built on the premise that there are important environmental components that affect performance in low SES high schools in Midwestern U.S. The environmental components used in this study are conceptualized to be effective leadership, collaborative teachers, parental involvement, supportive environment and ambitious instructions. This study would recommend for future studiesin other contexts such as middle and high SES communities, in training institutions, consultancy firms and lower grade schools.In addition, this study was based on a quantitative research design which facilitated a suitable statistical analysis through inferential and descriptive statistics. This study would recommend another study to be done on qualitative research design and compare the results of that study with that of this study to enable school decision makers and other stakeholders to make informed decisions.

From the research findings, this study found out that some of the five essential components explain on average $49.45 \%$ of mathematical scores in AYP, PSAE in low SES high schools in Midwestern U.S. Further the study found that some of the five essential components explain on average $40.8 \%$ of reading scores in AYP, PSAE in low SES high schools in Midwestern U.S. and the results of the study show that some of the five essential components explain on average $10.8 \%$ of graduation rate in low SES high schools in Midwestern U.S. This study therefore concludes that high schools should form initiative to implement effective ways to integrate in their schools the significant elements of the five essential components ( effective leadership, collaborative teachers, parental involvement, supportive environment and ambitious instructions) picking the most effective ones to improve academic achievement in school. 


\section{International Journal of Social Science and Economic Research}

ISSN: $2455-8834$

Volume:06, Issue:01 "January 2021"

\section{References}

Applegate, P. J. (2008). The qualities that differentiate high achieving and low achieving high poverty rural high schools: A transformative mixed methods study. ProQuest.

Augustine-Shaw, D. (2015). Leadership and learning: Identifying an effective design for mentoring new building leaders. Delta Kappa Gamma Bulletin, 81(2), 21-30.

Barile, J, Donohue, D., Anthony, E., Baker, A., Weaver, S., \& Henrich, C. (2012). Teacherstudent relationship climate and school outcomes: Implications for educational policy initiatives. Journal of Youth \& Adolescence, 41(3), 256-267.

Bektas, F., \&Nalcaci, A. (2013). Okuliklimil̇leogrenciBasarisiaraSindakiiliski (Turkish). International Journal of Eurasia Social Sciences/UluslararasiAvrasyaSosyalBilimlerDergisi, 4 (13), 1-13.

Bryk, A. S., Sebring, P. B., Allensworth, E., Easton, J. Q., \&Luppescu, S. (2010). Organizing schools for improvement: Lessons from Chicago. Chicago, IL: University of Chicago Press.

Ccsr.uchicago.edu. (2015). Surveys of CPS Schools/UChicago Consortium on Chicago School Research | the University of Chicago. Retrieved 24 April 2015, from https://ccsr.uchicago.edu/surveys.

Choi, N., \& Chang, M. (2011). Interplay among school climate, gender, attitude toward mathematics, and mathematics performance of middle school students. Middle Grades Research Journal, 6(1), 15-28.

Cronbach, L. J. (1951). Coefficient alpha and the internal structure of tests. Psychometrika, 16, 297-334.

DePoy, E., \& Gitlin, L. N. (2015). Introduction to research: Understanding and applying multiple strategies. Elsevier Health Sciences.

DiStefano, C., Monrad, D. M., May, R. J., McGuiness, P., \& Dickenson, T. (2007, April). Using school climate surveys to categorize schools and examine relationships with school achievement. In Meeting of the American Educational Research Association, Chicago, and IL.

Fan, W., Williams, C. M., \&Corkin, D. M. (2011). A multilevel analysis of student perceptions of school climate: The effect of social and academic risk factors. Psychology in the Schools, 48(6), 632-647. 


\section{International Journal of Social Science and Economic Research}

ISSN: $2455-8834$

Volume:06, Issue:01 "January 2021"

Faul, F., Erdfelder, E., Buchner, A., \& Lang, A.-G. (2009). Statistical power analyses using $\mathrm{G}^{*}$ Power 3.1: Tests for correlation and regression analyses. Behavior Research Methods, 41, 1149-1160..

Gregory, A., Cornell, D., \& Fan, X. (2012). Teacher safety and authoritative school climate in high schools. American Journal of Education, 118, 401- 425.

Illinois State Board of Education (ISBE). (2014). Illinois State Accountability Workbook. Retrieved 20 November 2015, from http://www.isbe.net/nclb/pdfs/accountability workbook.pdf-148.7KB - ISBE.

Kupzyk, K. A. (2011). The effects of simplifying assumptions in power analysis. Doctoral Dissertation, University of Nebraska.

McCoy, D. D., Roy, A., \&Sirkman, G. (2013). Neighborhood crime and school climate as predictors of elementary school academic quality: A cross-lagged panel analysis. American Journal of Community Psychology, 52(1/2), 128-140.

Mehta, S. B., Cornell, D., Fan, X., \& Gregory, A. (2013). Climate and school engagement in ninth-grade students. Journal of School Health, 83(1), 45-52.

Miller, A. E. (2010). School climate components that contribute to adequate yearly progress in elementary schools. Doctoral dissertation, Baker University.

O’Malley, M., Voight, A., Renshaw, L., \& Eklund, K. (2014). School climate, family structure, and academic achievement: A study of moderation effects. School Psychology Quarterly 10, 1045-1051. Doi: 10.1037/spq0000076.

Punch, K. F. (2013). Introduction to social research: Quantitative and qualitative approaches. Thousand Oaks, CA: Sage Publications.

Ragin, C. C. (2014). The comparative method: Moving beyond qualitative and quantitative strategies. Univ of California Press.

Sebastian, J., \&Allensworth, E. (2012). The influence of principal leadership on classroom instruction and student learning: A study of mediated pathways to learning. Educational Administration Quarterly, 48(4), 626-663.

Thompson, M. J., \& Crank, J. N. (2010). An Evaluation of Factors that Impact Positive School Climate for School Psychologists in a Time of Conflicting Educational Mandates. Online Submission. Retrieved 26 June 2015, from ERIC database. (ED507929)

U.S. Department of Education. (2015). Office of Planning, Evaluation, and Policy Development, Policy and Program Studies Service. Retrieved June 26, 2015, from 


\section{International Journal of Social Science and Economic Research}

http://www2.ed.gov/rschstat/eval/disadv/nclbaccountability/ nclb -accountabilityfinal.pdf.

Uchicagoimpact.org. (2015). 5Essentials/UChicago Impact Tools for Reliably Excellent Schooling/ The University of Chicago. Retrieved 24 April 2015, from http://uchicagoimpact.org/5essentials.

University of Chicago. (2013). UChicago impact tools for reliability excellent schooling. Unpublished raw data, Department of Education, University of Chicago, Chicago, IL. Retrieved 24 April 2015, from http://uchicagoimpact.org.

Urick, A. U., \& Bowers, A. J. (2014). The impact of principal perception on student academic climate and achievement in high school: How does it measure up? Journal of School Leadership, 24(2), 386-414.

Wang, W., Vaillancourt, T., Brittain, H. L., McDougall, P., Krygsman, A., Smith, D. ... \& Hymel, S. (2014). School climate, peer victimization, and academic achievement: Results from a multi-informant study. School Psychology Quarterly, 29(3), and 360.

Weijun, W., Vaillancourt, T., Brittain, H. L., Krygsman, A., Smith, D., Haltigan, J. D. ...\& Hymel, S. (2014). School climate, peer victimization, and academic achievement: Results from a multi-informant study. School Psychology Quarterly, 29(3), 360-377. doi: $10.1037 / \mathrm{spq} 0000084$.

Welsh, W. N. (2000). The effects of school climate on school disorder. The Annals of the American Academy of Political and Social Science, 567(1), 88-107.

White, N., La Salle, T., Ashby, J. S., \& Meyers, J. (2014). A brief measure of adolescent perceptions of school climate. School Psychology Quarterly, 29(3), 349. 